\title{
Isometric Hip and Knee Torque measurements as an outcome measure in Robot Assisted Gait Training
}

Sujay S Galen ${ }^{1,2,3}$ Celia J Clarke ${ }^{1,2}$, Alan N Mclean², David B Allan², Bernard A Conway ${ }^{1,2}$

1 Bioengineering Unit, University of Strathclyde, Glasgow, UK.

2 Scottish Centre for Innovation in Spinal Cord Injury (SCISCI), Queen Elizabeth National Spinal Injuries Unit, Southern General Hospital, Glasgow, UK.

3 Physical Therapy Program, Eugene Applebaum College of Pharmacy and Health Care Sciences, Wayne State University, Detroit, MI, USA.

*Correspondence to first author at

Physical Therapy Program

Wayne State University

259 Mack Avenue

Detroit, MI 48201.

USA.

Tel: +1 (313) 5775531

Fax: +1 (313) 5778685

e-mail: sujay.galen@wayne.edu

Keywords: Incomplete spinal cord injury, Lokomat, Peak torque, Dynamometry, Muscle strength, Body weight supported treadmill training. 


\begin{abstract}
Background: Strength changes in lower limb muscles following robot assisted gait training (RAGT) in subjects with incomplete spinal cord injury (ISCI) has not been quantified using objective outcome measures.
\end{abstract}

Objective: To record changes in the force generating capacity of lower limb muscles (recorded as peak voluntary isometric torque at the knee and hip), before, during and after RAGT in both acute and subacute/chronic ISCI subjects using a repeated measures study design.

Methods: Eighteen subjects with ISCI participated in this study (Age range: 26-63 years mean age $=49.3 \pm 11$ years). Each subject participated in the study for a total period of eight weeks, including 6 weeks of RAGT using the Lokomat system (Hocoma AG, Switzerland). Peak torques were recorded in hip flexors, extensors, knee flexors and extensors using torque sensors that are incorporated within the Lokomat.

Results: All the tested lower limb muscle groups showed statistically significant $(\mathrm{p}<0.001)$ increases in peak torques in the acute subjects. Comparison between the change in peak torque generated by a muscle and its motor score over time showed a non-linear relationship.

Conclusions: The peak torque recorded during isometric contractions provided an objective outcome measure to record changes in muscle strength following RAGT. 


\section{Introduction}

The primary sensory and motor consequences of spinal cord injury (SCI) are well known, and vary according to the level and extent of lesion. .However, with paralysis comes a secondary complication of muscle atrophy. Following injury, the onset of muscle atrophy can be rapid and is evident soon after injury(Dudley-Javoroski \& Shields, 2008). The loss of muscle cross sectional area in SCI subjects has been reported to be between 18 and $46 \%$ on average when compared with neurologically intact individuals (Giangregorio \& McCartney, 2006). This degree of muscle atrophy and the related loss of force generating capacity can contribute to functional impairment and can compromise progression of rehabilitation in SCI subjects. Accordingly, methods for early mobilization may mitigate against atrophy by either reversing or reducing the rate of muscle loss. In ISCI subjects receiving intensive gait rehabilitation, this is likely to be a factor that facilitates the functional recovery of gait (Dietz, Colombo, Jensen, \& Baumgartner, 1995).

Bodyweight supported treadmill training (BWSTT) has been shown to improve walking ability (Nymark et al., 1998; Postans, Hasler, Granat, \& Maxwell, 2004) in ISCI subjects and is increasingly being adopted within physical therapy programs (Hicks \& Martin Ginis, 2008). For acute subjects BWSTT also serves as a method for early lower limb mobilization and exercise.

In recent years the use of robotic assistance during BWSTT has emerged as an alternative to therapist assisted(Adams et al., 2006; Hicks et al., 2005) or FES assisted BWSTT(Postans et al., 2004) and may provide a more resource efficient method of delivering intensive and progressive gait training (Hornby, Zemon, \& Campbell, 2005). The Lokomat ${ }^{\circledR}$ (Hocoma AG, Switzerland) is a robotic driven gait orthosis (DGO) that provides robot assisted gait training (RAGT) using BWSTT. Although preliminary studies have shown that Lokomat 
training improves gait in both acute (Hornby et al., 2005), and chronic ISCI subjects (Wirz et al., 2005) there have been no studies documenting the associated changes in the force generating capacity of the lower limb muscles, in subjects as they progress through RAGT using BWSTT

Strength changes in lower limb muscles following locomotor training have been previously documented in ISCI subjects using objective outcome measures such as peak torque recorded using a Biodex dynamometer. (Jayaraman et al., 2008) Given that the Lokomat system is equipped with integrated torque sensors within the DGO exoskeleton, the device has the capability to be used as a dynamometer in its own right. Recently it has been shown that the peak torques, recorded using the torque sensors integrated within the DGO exoskeleton, provides data with good inter and intra-rater reliability in both healthy subjects and subjects with neuromuscular disorder.(Bolliger, Banz, Dietz, \& Lunenburger, 2008) This inbuilt capability provides the opportunity for monitoring the peak torques generated around hip and knee during voluntary isometric exertions, and has a potential use as a clinical measure to monitor the subject's progress through the rehabilitation programme (Bolliger et al., 2008; Lunenburger, Colombo, Riener, \& Dietz, 2004). In this study we set out to record the change in voluntary force generating capacity in the hip and knee flexors and extensor muscles, before, during and at the end of RAGT in both acute and subacute/chronic ISCI subjects. The quantitative force data is then compared with the equivalent manual muscle scores acquired from subjects as part of the standard neurological classification of spinal cord injury. (Marino et al., 2003)

\section{Methodology}

Eighteen subjects with ISCI participated in this study (Age range: 26-63 years mean age = $49.3 \pm 11$ years) of which five were classified as sub acute/chronic subjects ( $>6$ months from 
time of injury) and thirteen were classified as acute subjects ( $<6$ months from the time of injury). Subjects were recruited if they were

- Acute or Chronic ISCI subjects graded as AIS classification C/D.(Marino et al., 2003)

- Between the ages of 18-65 years.

- Assessed as medically stable by an (independent) physician.

Subjects were not recruited if they had

- Complications requiring immobilization such as fractures and pressure sores.

- Osteoporosis or contractures limiting range of motion.

- A bodyweight of over $130 \mathrm{~kg}$ or thigh length over $47 \mathrm{cms}$ (Lokomat restrictions).

Ethics approval was obtained from the National Health Service (NHS) regional ethics committee and subjects were recruited from the Queen Elizabeth National Spinal Injuries Unit, Glasgow. The details of the subjects who participated in the study are provided in Table1.

\section{Insert Table 1 here.}

Informed and signed consent was obtained from all subjects prior to the start of the study. Each subject participated in the study for a total period of 8 weeks. A repeated measures study design was used. A battery of neuro-physiological and functional outcome measures were used to record the subject's baseline and final measures during week 1 and week 8 of the study respectively. RAGT was provided using the Lokomat for an hour each week day (Monday to Friday) from Week 2 to Week 7 (a total of 6 weeks) for each subject. For more details on the outcome measures used in this study, refer to Ellaway et al 2010. (Ellaway et 
al.) When RAGT began, subjects walked on the Lokomat at a speed of 1-1.2 $\mathrm{km} / \mathrm{h}$ with body weight support between $80-70 \%$ of their body weight. These parameters were progressed depending on the subject's tolerance. The speed of walking during RAGT was increased to a maximum of $2 \mathrm{~km} / \mathrm{h}$ and the body weight support was reduced at a rate depending on the subject's ability to maintain the knee in extension during the midstance phase of the gait cycle.

The peak torque generated during an isometric contraction of the hip and knee flexor and extensor muscles in the lower limb were recorded during each of the six weeks of RAGT. The assessments were performed during the middle (Wednesday) of each training week, before the subject had commenced the scheduled training for the day. This protocol was adopted in order to prevent any effects including muscle fatigue that subjects may experience following training, which may influence the subject's ability to perform a peak isometric contraction. The subjects were positioned in the DGO as described by Bolliger et al 2008.(Bolliger et al., 2008) Each of the four muscle groups were tested one at a time, first on the right side and then on the left side. For example if the subject was asked to perform hip flexion, a demonstrator standing in front of the subject illustrated the task required and encouraged the subject to achieve maximal isometric contraction when cued to start. The subjects were given a countdown of 3-2-1 following which the subject attempted the isometric contraction by pushing against the fixed DGO as described by Bolliger et al 2008(Bolliger et al., 2008). Each of the measurements (hip flexion and extension and knee flexion and extension) was performed three times, and the peak torque generated during an isometric contraction was recorded. A short rest period was provided between each exertion. 
To compare the force generating capacities of the muscles between subjects, the peak torque generated was expressed as a percentage of the overall maximum torque recorded from each of the muscle groups during the six week training period. The data was first individually analyzed for each subject. A descriptive analysis was performed to identify any trends that can suggest a change in the force generating capacity in each of the muscle groups tested. The data was then pooled separately for subacute/chronic and acute subjects, to study the change in the peak torques generated within these cohorts. The Friedman's test was used to establish if the data showed any significant difference in the generated peak torques over the training period of six weeks. A p-value of $p<0.05$ was considered to be significant. If the Friedman's test indicated that there were significant differences in the generated peak torques over the six weeks of training, a Wilcoxon signed rank test was used to identify the between week differences in the generated peak torque. All tests were performed using SPSS (version 18) software. The lower limb motor score for the hip flexors and knee extensors (the two muscle groups assessed as part of the ASIA assessment), were compared with the peak torque generated by the respective muscle group. The subject's locomotor function was also assessed using the walking index in spinal cord injury (WISCI II scale) (Dittuno \& Dittuno Jr, 2001) performed during week 1 (before) and week 8 (after) the full RAGT programme.

\section{Results}

Locomotor function (measured using WISCI II) following RAGT showed a greater increase in acute subjects compared to subacute/chronic subjects (Figure 1).

\section{Insert Figure 1 here.}

The peak torque generated as a result of isometric contraction of the muscle was successfully recorded in the hip flexors and extensors and knee flexors and extensors in all subjects. Examples of the peak torques recorded in two acute subjects (P15 and P10) are presented in 
Figures $2 \mathrm{a}$ and $2 \mathrm{~b}$ respectively. Both subjects (P15 and P10) were classified as AIS D on the ASIA scale. Subject P10 remained non-ambulant both prior to and after the RAGT and hence was given a score of 0 on the WISCI II scale. Subject P15 was unable able to walk prior to the RAGT but following six weeks of Lokomat training the subject was able to walk with the assistance of single elbow crutch and without any braces, hence progressing from a score of 0 to a score of 19 on the WISCI II scale. The change in ambulatory capacity in subject P15 was accompanied by an increase in peak torque generated as a result of isometric contraction of the leg muscles that were tested (Figure 2a). In contrast, P10 (Figure 2b) who remained non-ambulant showed little or no change in the peak torque generated by the lower limb muscles tested over the six weeks of RAGT.

\section{Insert Figure $2(2 \mathrm{a} \& 2 \mathrm{~b})$ here.}

The normalized values of the peak torques generated in the hip flexor and extensors (Figure $3 \mathrm{a}$ and $3 \mathrm{~b}$ ) and knee flexors and extensors (Figure $4 \mathrm{a}$ and $4 \mathrm{~b}$ ) were analyzed separately for acute and subacute/chronic subjects. In the subacute/chronic subjects the pooled data showed no significant change in the peak torque generated throughout the six weeks of RAGT (Figure 3 and 4). This contrasts with data from acute subjects who show a gradual increase in their peak torque over the six weeks of RAGT (Figure 3 and 4).

\section{Insert Figures 3(3a, 3b) \& 4(4a,4b) here.}

The gains in peak torques in acute subjects were more evident after completion of 3 or more weeks of training (Figure 3 and 4). Friedman's test performed on the pooled data from subacute/chronic subjects showed that the change in peak torque over the 6 weeks were not significant in all four muscle groups (hip flexor $\mathrm{p}=0.656$, hip extensor $\mathrm{p}=0.608$, knee flexor $\mathrm{p}=0.192$ and knee extensor $\mathrm{p}=0.156$ ). Friedman's test performed on the pooled data from acute subjects showed that the change in peak torque over the 6 weeks in acute subjects were highly significant in all four muscle groups ( $\mathrm{p}<0.001$ in all four muscle groups). Therefore a 
Wilcoxon signed rank test was used to compare the peak torques recorded between the training weeks in acute subjects. The results of these tests along with their $p$ value are presented in Table 2 .

\section{Insert Table 2 here.}

An increase in the lower limb motor score corresponded to an increase in the peak torque generated by the muscles that were tested. However this correlation between the motor score and peak torque was not a linear relationship (Figure 5a,5b,6a \& 6b). When the subject had the ability to perform full ROM against gravity in both lower limbs i.e. having a lower limb motor score $>6$, the between subject variability of the peak torque measure increased. This observation was valid for both acute and sub-acute/chronic subjects who had participated in this study. In addition, subacute/chronic subjects had higher lower limb motor score in both hip and knee joints compared to the acute subjects. However, an increase in lower limb motor scores in subacute/chronic subjects was not necessarily accompanied by an increase in the peak torque generated by the muscle being assessed (Figure $6 a \& 6$ ).

\section{Insert Figures 5(5a,5b) \& 6(6a,6b) here.}

\section{Discussion}

This study has succeeded in objectively recording changes in muscle strength in both acute and subacute/chronic subjects with ISCI during their participation in a 6 week intensive Lokomat RAGT programme. An increase in the recorded peak torque in the lower limb muscles was generally accompanied by a better ambulatory function in acute subjects as illustrated in the example shown in Figure 2a. On beginning RAGT this acute subject(P15) was unable to stand or ambulate but over the 6 week period of RAGT the subject improved to a point where a 10 meter walk could be completed without the use of walking aids (WISCI II 
score rising from 0 to 19). Improvements in gait function were observed in most acute subjects and this functional gain was accompanied by an increased peak isometric torque measurement. For the acute subjects, the functional gains in gait and muscle power are likely to reflect the combination of the natural recovery process post injury (Basso, 2000) supplemented by the impact of the intensive RAGT programme (Dietz, 2008). However, for some of the acute subjects, and the majority of chronic subjects, little or no change was observed in the recorded peak torques. Significantly, these subjects also failed to demonstrate significant improvements in walking ability as measured by WISCI II (refer to subject P10 illustrated in Figure 2b). The lack of significant changes in muscle strength in these subjects highlight that time post injury should be considered as an important factor to be taken into account in determining a gait rehabilitation programme for spinal cord injured subjects. In addition, the lack of evidence for RAGT promoting muscle strength changes in chronic subjects suggests that either the level of exercise provided by the training in this cohort was not sufficient to boost the force generating capacity of the muscle or that, they had reached a ceiling point in voluntary muscle performance post injury, thus re-emphasizing the criticality of the time window post injury for effective rehabilitation.

From the evidence presented in this study, it is clear that for those subjects that respond to the RAGT that significant gains in the force generating capacity of the lower limb muscles can be observed by the third week of training (Table 2) in acute ISCI subjects. Provided subjects are within the acute phase, this change in muscle strength does not seem to be affected by duration between the initial injury and the time when subject commenced the RAGT(Table 1). The fact that significant changes were observed after 3 weeks of RAGT may imply that either a threshold level or minimum volume of training is required before any gains can be 
identified. Our observation also suggests that in acute subjects RAGT facilitates functional outcome above that produced by natural recovery processes on their own.

The observation that acute subjects who positively responded to RAGT had significant increase in peak torques within the first 3 weeks of training, suggests that this type of quantitative monitoring could also be considered as a useful marker in identifying subjects who are positively responding to RAGT using BWSTT. Accordingly, a change in peak torques generated by the lower limb muscles that exceeds the baseline measures, has the potential to be used as an indicator that helps the clinician to decide whether to continue training or to alter the rehabilitation strategy. This relationship between training time and muscle strength gain has not been previously reported in the literature. We have previously reported a similar pattern of improvement in gait function following Lokomat training.(Galen, Clarke, Allan, \& Conway, 2011)

The statistical analysis showed that acute subjects made more gains compared to the subacute/ chronic subjects who participated in this study (Figures $3 \& 4$ ). This finding may not entirely support the findings of previous studies that investigated effects of BWSTT(Adams et al., 2006; Hicks et al., 2005; Wirz et al., 2005) in subacute/chronic SCI subjects. This may be due to the fact that all subacute/chronic subjects who participated in this study had already completed their rehabilitation and were able to perform some form of ambulation either at a functional or therapeutic level using either braces or assistance. As stated above, this perhaps indicates a ceiling effect on any further muscle strength gains or that the added training did not significantly alter the outcome in this group. A further option is that in the chronic subjects the threshold level of activity to induce new muscle hypertrophy is elevated compared with that in acute subjects (i.e. loss of muscle plasticity) 
and further research will be required to explain these findings. It also needs to be noted that there were fewer chronic ISCI subjects in this study $(n=5)$ than acute subjects $(n=13)$. A larger group of subacute/chronic subjects with ISCI with more varied levels of mobility may need to be studied to fully understand the capacity of intensive RAGT to induce strength. Moreover the magnitude of the peak torque generated by the hip flexors and knee extensors were almost the same if not much greater in the subacute/chronic subjects compared to the acute subjects (Figures 5-6). Muscle atrophy secondary to SCI(Giangregorio \& McCartney, 2006), has been reported previously, and has been considered a complication that has detrimental effects. However in the cohort of ISCI subjects who participated in this study, muscle strength seems to have been preserved. This is likely to be due to the fact that these subacute/chronic subjects were ambulant; therefore a better ambulatory capacity (Figure 2) following ISCI seems to stabilize muscle strength.

Manual muscle testing is an important component of the standard neurological classification of spinal cord injury (ASIA) scoring system. In this study we observed a non-linear relation between the peak torque generated as a result of isometric contraction and lower limb motor scores. The lack of a linear correlation between a quantitative measure that produces continuous data and measure that uses an ordinal scale to quantify muscle strength is expected and reflects the lack of resolution available within the manual muscle testing scoring method particularly when individual muscle groups are rated as grade 4 or 5 . At these grades the lack of precision in the manual muscle test scoring system makes it difficult to account for improvement in the force generating capacity of the muscle. This can explain the greater range of recorded peak torque values seen in cases where the combined lower limb motor score exceeds six (Figures 5-6). 
RAGT, in addition to having the potential to improve the force generating capacity of the lower limb muscles and gait function in responding ISCI subjects has also been reported to have an exercise impact on cardiovascular fitness and so contributes to improvements in the overall health and wellbeing of subjects irrespective of time post injury.(Jack, Purcell, Allan, \& Hunt, 2011)

In recent years laboratory based studies on animal models of spinal cord injury have also demonstrated that intensive locomotor training when combined with other regenerative or pharmacological treatments produce better outcomes than when delivered on their own.(Edgerton, Kim, Ichiyama, Gerasimenko, \& Roy, 2006) This suggests that when designing new pharmaceutical or regenerative treatments careful consideration should be given to the level and intensity of any concomitant rehabilitation programme. Use of interventions such as RAGT may offer advantages in such trials as both the dose and intensity of the rehabilitation programme can be easily monitored and standardized and that the integrated dynamometry provides for simple longitudinal collection of a set of important outcome measures.

\section{Conclusion}

This study has recorded in ISCI subjects patterns of change in isometric peak torque in lower limb muscles over a 6 week programme of RAGT. Peak torque seems to increase most in those subjects who achieve the greatest change in locomotor function at the end of the 6 week training period. The measurement of isometric peak torque and its use as an outcome measure provides a more objective method for longitudinal monitoring of the force generating capacity of the muscle in subjects post injury, compared to the use of manual muscle testing. The differential effects of Lokomat training on muscle strength seen in acute verses subacute/chronic ISCI subjects also merits further investigation using a larger sample 
of subjects. Similarly, regular monitoring for change in the force generating capacity of the lower limb muscles can provide a useful yet simple method for personalizing the rehabilitation programme and in identifying responding subjects.

\section{Declaration of Interest}

None declared.

\section{Acknowledgement}

The Subjects and staff at the Queen Elizabeth National Spinal Injuries Unit, Glasgow. This study was funded by the International Spinal Research Trust, Clinical Initiative program (CLI004) and the Henry Smith Charity. 


\section{References}

Adams, M. M., Ditor, D. S., Tarnopolsky, M. A., Phillips, S. M., McCartney, N., \& Hicks, A. L. (2006). The effect of body weight-supported treadmill training on muscle morphology in an individual with chronic, motor-complete spinal cord injury: A case study. J Spinal Cord Med, 29(2), 167-171.

Basso, D. M. (2000). Neuroanatomical substrates of functional recovery after experimental spinal cord injury: implications of basic science research for human spinal cord injury. Phys Ther, 80(8), 808-817.

Bolliger, M., Banz, R., Dietz, V., \& Lunenburger, L. (2008). Standardized voluntary force measurement in a lower extremity rehabilitation robot. J Neuroeng Rehabil, 5, 23. doi: 1743-0003-5-23 [pii]

$10.1186 / 1743-0003-5-23$

Dietz, V. (2008). Body weight supported gait training: from laboratory to clinical setting. Brain Res Bull, 76(5), 459-463. doi: S0361-9230(08)00111-1 [pii]

10.1016/j.brainresbull.2008.02.034

Dietz, V., Colombo, G., Jensen, L., \& Baumgartner, L. (1995). Locomotor capacity of spinal cord in paraplegic patients. Ann Neurol, 37(5), 574-582. doi: 10.1002/ana.410370506

Dittuno, P. L., \& Dittuno Jr, J. F., Jr. (2001). Walking index for spinal cord injury (WISCI II): scale revision. Spinal Cord, 39(12), 654-656. doi: 10.1038/sj.sc.3101223 [doi]

Dudley-Javoroski, S., \& Shields, R. K. (2008). Muscle and bone plasticity after spinal cord injury: review of adaptations to disuse and to electrical muscle stimulation. J Rehabil Res Dev, 45(2), 283-296.

Edgerton, V. R., Kim, S. J., Ichiyama, R. M., Gerasimenko, Y. P., \& Roy, R. R. (2006). Rehabilitative therapies after spinal cord injury. J Neurotrauma, 23(3-4), 560-570. doi: 10.1089/neu.2006.23.560

Ellaway, P. H., Kuppuswamy, A., Balasubramaniam, A. V., Maksimovic, R., Gall, A., Craggs, M. D., ... van Hedel, H. J. Development of quantitative and sensitive assessments of physiological and functional outcome during recovery from spinal cord injury: a clinical initiative. Brain Res Bull, 84(4-5), 343-357. doi: S0361-9230(10)00187-5 [pii]

10.1016/j.brainresbull.2010.08.007

Galen, S. S., Clarke, C. J., Allan, D. B., \& Conway, B. A. (2011). A portable gait assessment tool to record temporal gait parameters in SCl. Med Eng Phys, 33(5), 626-632. doi: S13504533(11)00007-5 [pii]

10.1016/j.medengphy.2011.01.003

Giangregorio, L., \& McCartney, N. (2006). Bone loss and muscle atrophy in spinal cord injury: epidemiology, fracture prediction, and rehabilitation strategies. J Spinal Cord Med, 29(5), 489-500.

Hicks, A. L., Adams, M. M., Ginis, K. M., Giangregorio, L., Latimer, A., Phillips, S. M., \& McCartney, N. (2005). Long-term body-weight-supported treadmill training and subsequent follow-up in persons with chronic SCl: effects on functional walking ability and measures of subjective well-being. Spinal Cord, 43(5), 291-298. doi: DOI 10.1038/sj.sc.3101710

Hicks, A. L., \& Martin Ginis, K. A. (2008). Treadmill training after spinal cord injury: It's not just about the walking. J Rehabil Res Dev, 45(2), 241-248.

Hornby, T. G., Zemon, D. H., \& Campbell, D. (2005). Robotic-assisted, body-weight-supported treadmill training in individuals following motor incomplete spinal cord injury. Phys Ther, $85(1), 52-66$ 
Jack, L. P., Purcell, M., Allan, D. B., \& Hunt, K. J. (2011). The metabolic cost of passive walking during robotics-assisted treadmill exercise. Technol Health Care, 19(1), 21-27. doi: $8765332286513 V 12$ [pii]

10.3233/THC-2011-0608

Jayaraman, A., Shah, P., Gregory, C., Bowden, M., Stevens, J., Bishop, M., . . Vandenborne, K. (2008). Locomotor training and muscle function after incomplete spinal cord injury: case series. J Spinal Cord Med, 31(2), 185-193.

Lunenburger, L., Colombo, G., Riener, R., \& Dietz, V. (2004). Biofeedback in gait training with the robotic orthosis Lokomat. Conf Proc IEEE Eng Med Biol Soc, 7, 4888-4891. doi: 10.1109/IEMBS.2004.1404352

Marino, R. J., Barros, T., Biering-Sorensen, F., Burns, S. P., Donovan, W. H., Graves, D. E., . . Priebe, M. M. (2003). International standards for neurological classification of spinal cord injury. $J$ Spinal Cord Med, 26 Suppl 1, S50-56.

Nymark, J., DeForge, Z., Barbeau, H., Badour, M., Bercovitch, S., \& Tomas, J. (1998). Body weight support treadmill gait training in the subacute recovery phase of incomplete spinal cord injury. Journal of Neurologic Rehabilitation, 12(3), 119-138.

Postans, N. J., Hasler, J. P., Granat, M. H., \& Maxwell, D. J. (2004). Functional electric stimulation to augment partial weight-bearing supported treadmill training for patients with acute incomplete spinal cord injury: A pilot study. Arch Phys Med Rehabil, 85(4), 604-610. doi: S000399930301027X [pii]

Wirz, M., Zemon, D. H., Rupp, R., Scheel, A., Colombo, G., Dietz, V., \& Hornby, T. G. (2005). Effectiveness of automated locomotor training in patients with chronic incomplete spinal cord injury: a multicenter trial. Arch Phys Med Rehabil, 86(4), 672-680. doi: S0003999304013279 [pii]

10.1016/j.apmr.2004.08.004 


\begin{tabular}{|c|c|c|c|c|c|c|c|}
\hline Subject & $\begin{array}{c}\text { Age } \\
\text { (Years) }\end{array}$ & Sex & $\begin{array}{l}\text { Acute/ } \\
\text { Chronic }\end{array}$ & $\begin{array}{c}\text { Time } \\
\text { Since } \\
\text { Injury } \\
\text { (weeks) }\end{array}$ & Syndrome & $\begin{array}{c}\text { Neurological } \\
\text { Level }\end{array}$ & $\begin{array}{l}\text { ASIA } \\
\text { Grade }\end{array}$ \\
\hline P1 & 26 & $\mathrm{M}$ & Chronic & 84 & Brown-Sequard & $\mathrm{C} 4$ & $\mathrm{D}$ \\
\hline $\mathbf{P 2}$ & 49 & $\mathrm{M}$ & Acute & 13 & Anterior Cord & $\mathrm{T} 8$ & $\mathrm{D}$ \\
\hline P3 & 61 & $\mathrm{M}$ & Acute & 20 & Central Cord & $\mathrm{C} 3$ & $\mathrm{D}$ \\
\hline P4 & 30 & $\mathrm{M}$ & Chronic & 44 & Anterior Cord & L1 & $\mathrm{C}$ \\
\hline P5 & 48 & $F$ & Acute & 4 & Anterior Cord & T11 & $\mathrm{D}$ \\
\hline P6 & 61 & $\mathrm{M}$ & Chronic & 26 & Central Cord & $\mathrm{C} 4$ & $\mathrm{D}$ \\
\hline P7 & 59 & $\mathrm{M}$ & Chronic & 169 & Central Cord & $\mathrm{C} 4$ & $\mathrm{D}$ \\
\hline P8 & 59 & $\mathrm{M}$ & Acute & 14 & Central Cord & $\mathrm{C} 4$ & $\mathrm{D}$ \\
\hline P9 & 58 & $\mathrm{M}$ & Acute & 8 & Anterior Cord & T11 & $\mathrm{D}$ \\
\hline P10 & 30 & $\mathrm{M}$ & Acute & 18 & Central Cord & $\mathrm{C} 4$ & $\mathrm{D}$ \\
\hline P11 & 63 & $\mathrm{M}$ & Acute & 8 & Central Cord & $\mathrm{C} 5$ & $\mathrm{D}$ \\
\hline P12 & 42 & $\mathrm{M}$ & Acute & 6 & Anterior Cord & T9 & $\mathrm{C}$ \\
\hline P13 & 57 & $F$ & Acute & 13 & Anterior Cord & $\mathrm{T} 2$ & $\mathrm{C}$ \\
\hline P14 & 53 & $\mathrm{M}$ & Chronic & 110 & Central Cord & $\mathrm{C} 5$ & $\mathrm{D}$ \\
\hline P15 & 44 & $\mathrm{M}$ & Acute & 5 & Anterior Cord & $\mathrm{T} 8$ & $\mathrm{D}$ \\
\hline P16 & 42 & $\mathrm{~F}$ & Acute & 12 & Central Cord & $\mathrm{C} 5$ & $\mathrm{C}$ \\
\hline P17 & 57 & $\mathrm{M}$ & Acute & 8 & Anterior Cord & $\mathrm{T} 3$ & $\mathrm{D}$ \\
\hline P18 & 31 & $\mathrm{~F}$ & Acute & 11 & Central Cord & $\mathrm{C} 4$ & $\mathrm{C}$ \\
\hline
\end{tabular}

Table 1 : Details of Subjects who had participated in the study. Subjects who were $<6$ months post injury at the time of recruitment were classified as acute and the rest were classified as Chronic. $\mathrm{M}=$ Male and $\mathrm{F}=$ Female. 


\begin{tabular}{|c|c|c|c|c|c|c|c|}
\hline Acute & & Mean & $\begin{array}{l}\text { Standard } \\
\text { deviation }\end{array}$ & Median & $\begin{array}{l}\text { Upper } \\
\text { quartile }\end{array}$ & $\begin{array}{l}\text { Lower } \\
\text { quartile }\end{array}$ & $p$ value \\
\hline \multirow[t]{6}{*}{ Hip flexion } & Week1 & 52.96 & 23.12 & 49.42 & 36.85 & 72.37 & \\
\hline & Week2 & 57.43 & 27.22 & 61.31 & 34.81 & 79.21 & 0.526 \\
\hline & Week3 & 79.60 & 16.14 & 77.7 & 66.46 & 95.77 & $<0.001$ \\
\hline & Week4 & 68.88 & 16.58 & 69.44 & 58.63 & 81.17 & 0.002 \\
\hline & Week5 & 82.71 & 17.28 & 88.99 & 62.15 & 100.00 & 0.001 \\
\hline & Week6 & 89.06 & 14.89 & 93.21 & 82.84 & 100.00 & $<0.001$ \\
\hline \multirow[t]{6}{*}{$\begin{array}{l}\text { Hip } \\
\text { Extension }\end{array}$} & Week1 & 62.33 & 15.27 & 57.08 & 53.69 & 72.31 & \\
\hline & Week2 & 71.38 & 18.32 & 72.85 & 58.94 & 85.40 & 0.025 \\
\hline & Week3 & 81.72 & 14.37 & 84.3 & 71.47 & 94.79 & $<0.001$ \\
\hline & Week4 & 85.29 & 10.08 & 84.57 & 77.13 & 94.21 & $<0.001$ \\
\hline & Week5 & 89.22 & 9.95 & 91.09 & 84.90 & 96.90 & $<0.001$ \\
\hline & Week6 & 96.41 & 7.73 & 100 & 96.74 & 100.00 & $<0.001$ \\
\hline \multirow[t]{6}{*}{ Knee Flexion } & Week1 & 47.20 & 17.90 & 47.03 & 38.25 & 62.36 & \\
\hline & Week2 & 70.14 & 17.32 & 71.46 & 57.19 & 84.42 & $<0.001$ \\
\hline & Week3 & 71.05 & 20.08 & 75.1 & 57.32 & 85.23 & $<0.001$ \\
\hline & Week4 & 77.97 & 15.85 & 79.44 & 65.96 & 91.75 & $<0.001$ \\
\hline & Week5 & 82.65 & 19.65 & 88.08 & 74.24 & 98.53 & $<0.001$ \\
\hline & Week6 & 91.44 & 13.83 & 100 & 84.00 & 100.00 & $<0.001$ \\
\hline \multirow[t]{6}{*}{$\begin{array}{l}\text { Knee } \\
\text { Extension }\end{array}$} & Week1 & 58.50 & 17.78 & 58.57 & 45.96 & 74.42 & \\
\hline & Week2 & 52.79 & 26.84 & 58.25 & 26.94 & 75.73 & 0.779 \\
\hline & Week3 & 79.85 & 18.75 & 82.21 & 75.56 & 97.68 & $<0.001$ \\
\hline & Week4 & 69.26 & 21.74 & 73.54 & 52.16 & 82.64 & $<0.001$ \\
\hline & Week5 & 81.56 & 16.55 & 83.28 & 71.89 & 94.87 & 0.001 \\
\hline & Week6 & 91.19 & 14.65 & 100 & 87.45 & 100.00 & $<0.001$ \\
\hline
\end{tabular}

Table 2: Change in normalised peak torque compared to week 1 . All statistically significant differences $(p<0.05)$ are highlighted in grey cells. 
Figure1 : Change in ambulatory capacity (WISCI II score) before(Pre-intervention) and after(Postintervention) lokomat training (RAGT) in acute and subacute/chronic subjects.

Figure2a and 2b: Peak Torques recorded in subjects P15 and P10 across key muscle groups in the lower limb during the six weeks of RAGT.

Figure 3a and 3b: Normalised peak torques presented as pooled data for chronic and acute subjects.

Figure 4a and 4b: Normalised peak torques presented as pooled data for chronic and acute subjects.

Figure $\mathbf{5 a}$ and $\mathbf{5} \mathbf{b}$ : Peak Torque generatd as a result of isometric contraction of the hip flexor and knee extensor muscles, compared against the Lower limb motor score (ASIA Score), for each of the respective muscle in acute subjects. Results of ambulant subjects are shown as a solid line and results from non-ambulant subjects are shown using dashed line. Intial measures are denoted by open circles and final measures are denoted by filled circles.

Figure $6 a$ and 6 b: Peak Torque generatd as a result of isometric contraction of the hip flexor and knee extensor muscles, compared against the Lower limb motor score (ASIA Score), for each of the respective muscle in subacute/chronic subjects. Intial measures are denoted by open circles and final measures are denoted by filled circles. 
Change in WISCI II score before before and after lokomat training

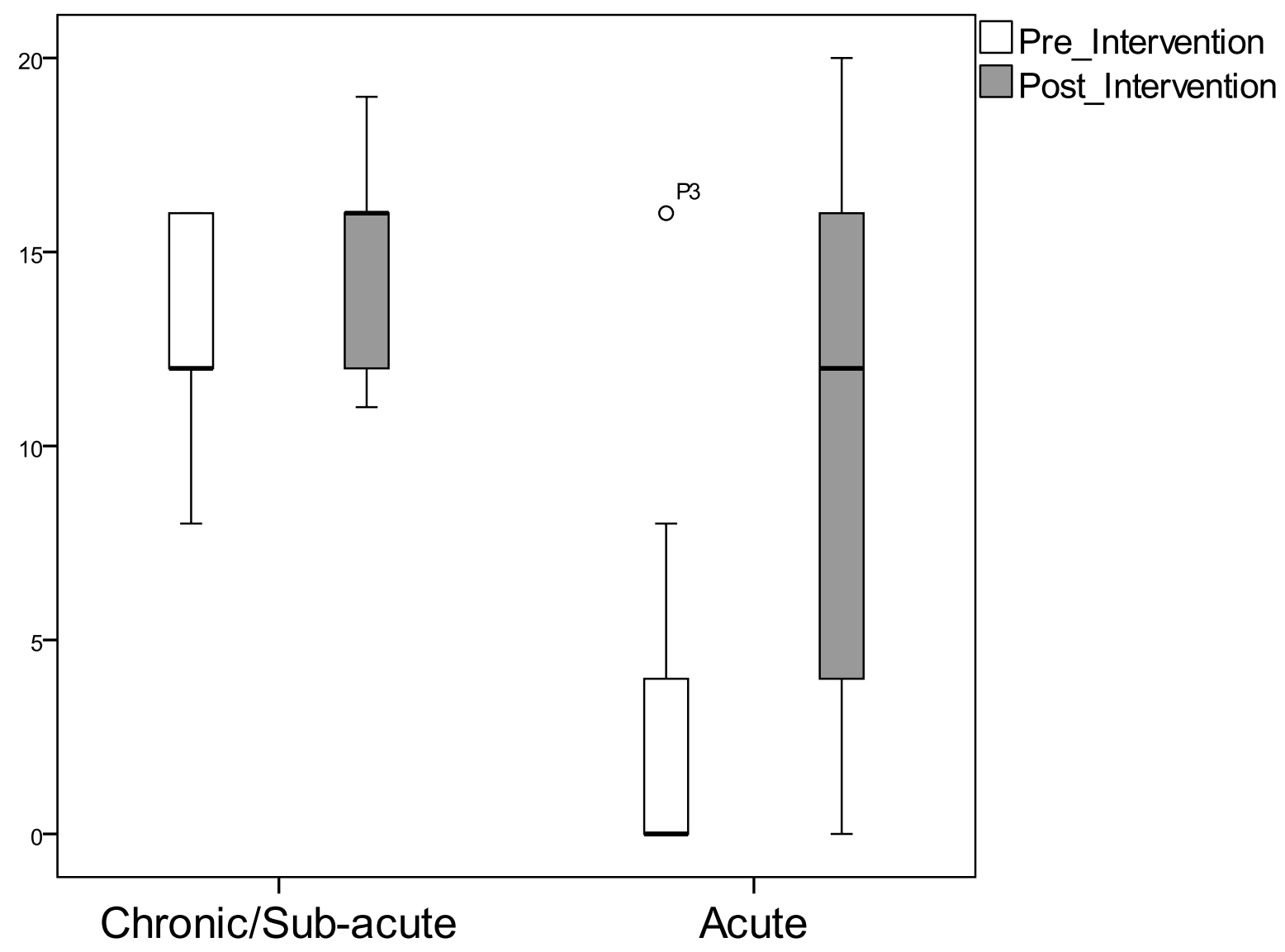

Figure1 : Change in ambulatory capacity (WISCI II score) before(Pre-intervention) and after(Postintervention) lokomat training (RAGT) in acute and subacute/chronic subjects. 

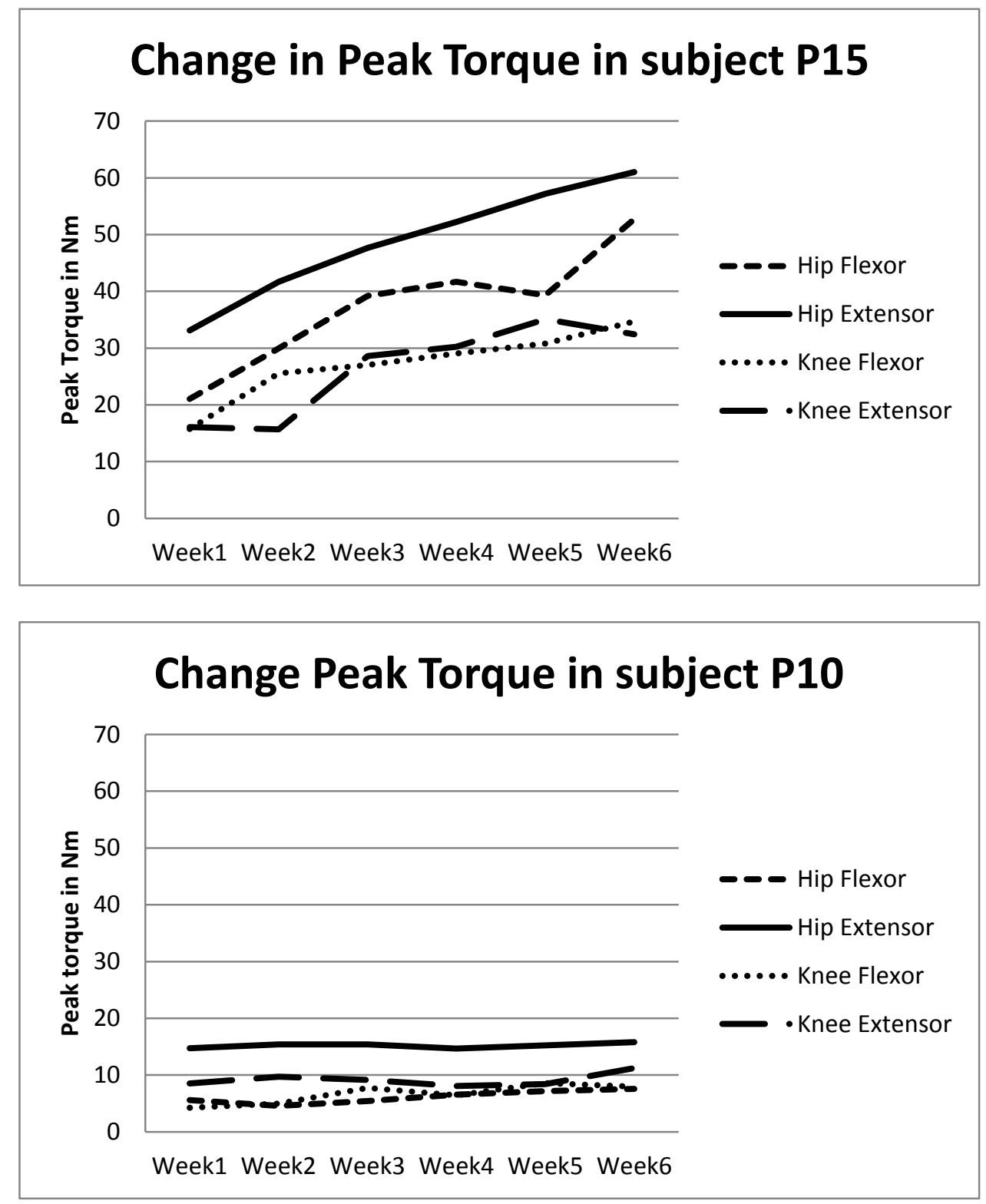

Figure2a and 2b: Peak Torques recorded in subjects P15 and P10 across key muscle groups in the lower limb during the six weeks of RAGT. 

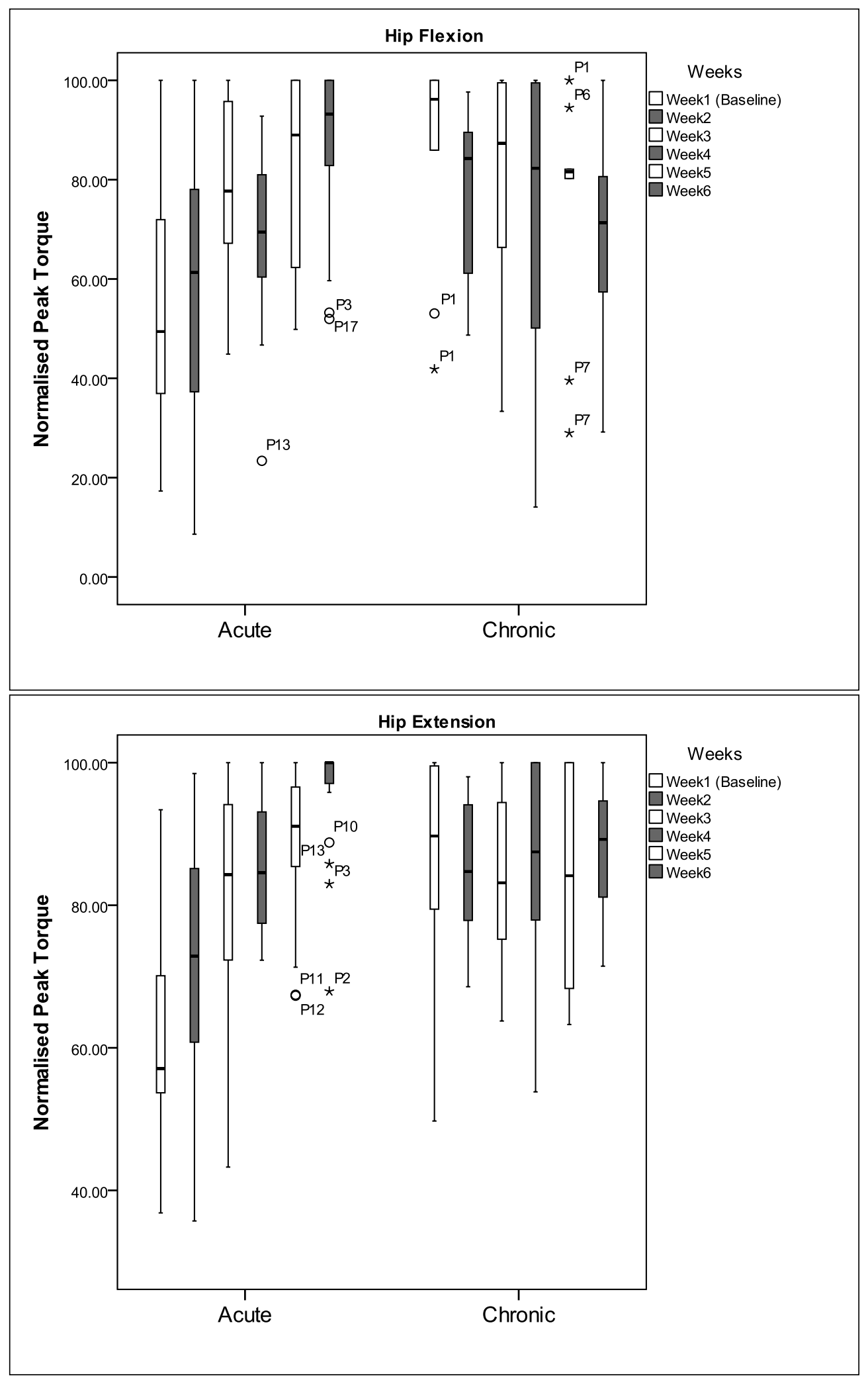

Figure 3a and 3b: Normalised peak torques presented as pooled data for chronic and acute subjects. 

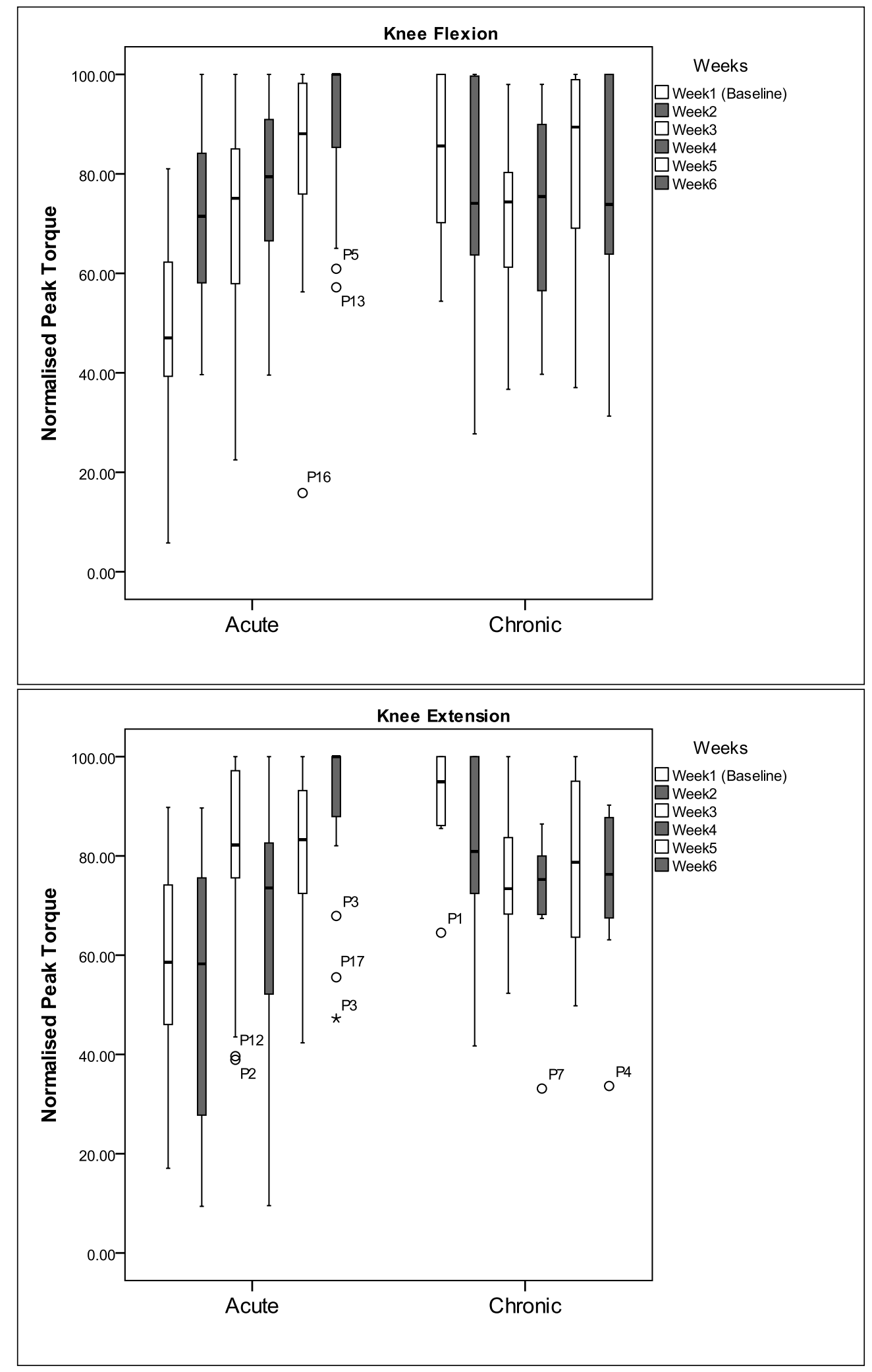

Figure 4a and 4b: Normalised peak torques presented as pooled data for chronic and acute subjects. 


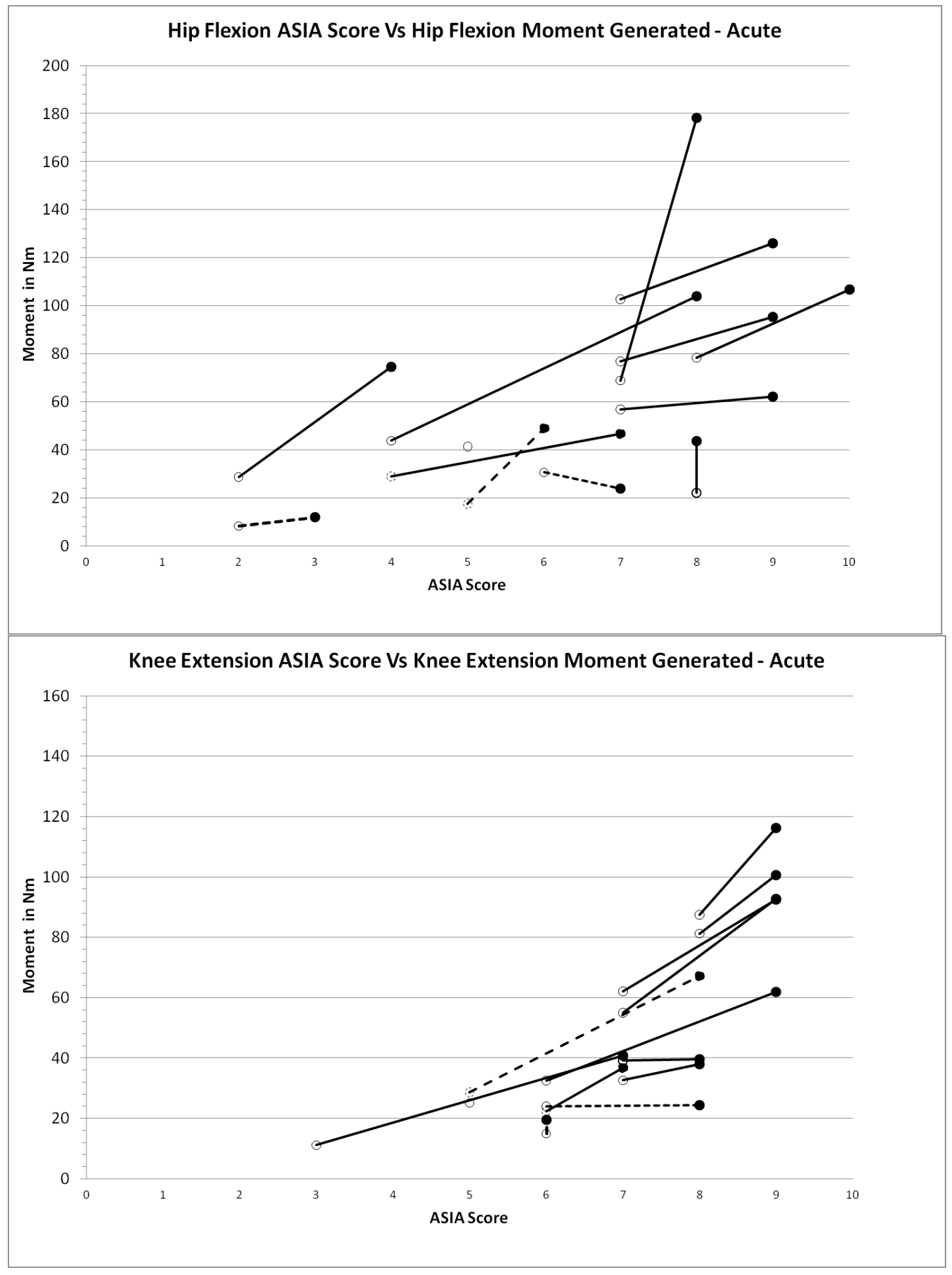

Figure $\mathbf{5 a}$ and $\mathbf{5} \mathbf{b}$ : Peak Torque generatd as a result of isometric contraction of the hip flexor and knee extensor muscles, compared against the Lower limb motor score (ASIA Score), for each of the respective muscle in acute subjects. Results of ambulant subjects are shown as a solid line and results from non-ambulant subjects are shown using dashed line. Intial measures are denoted by open circles and final measures are denoted by filled circles. 


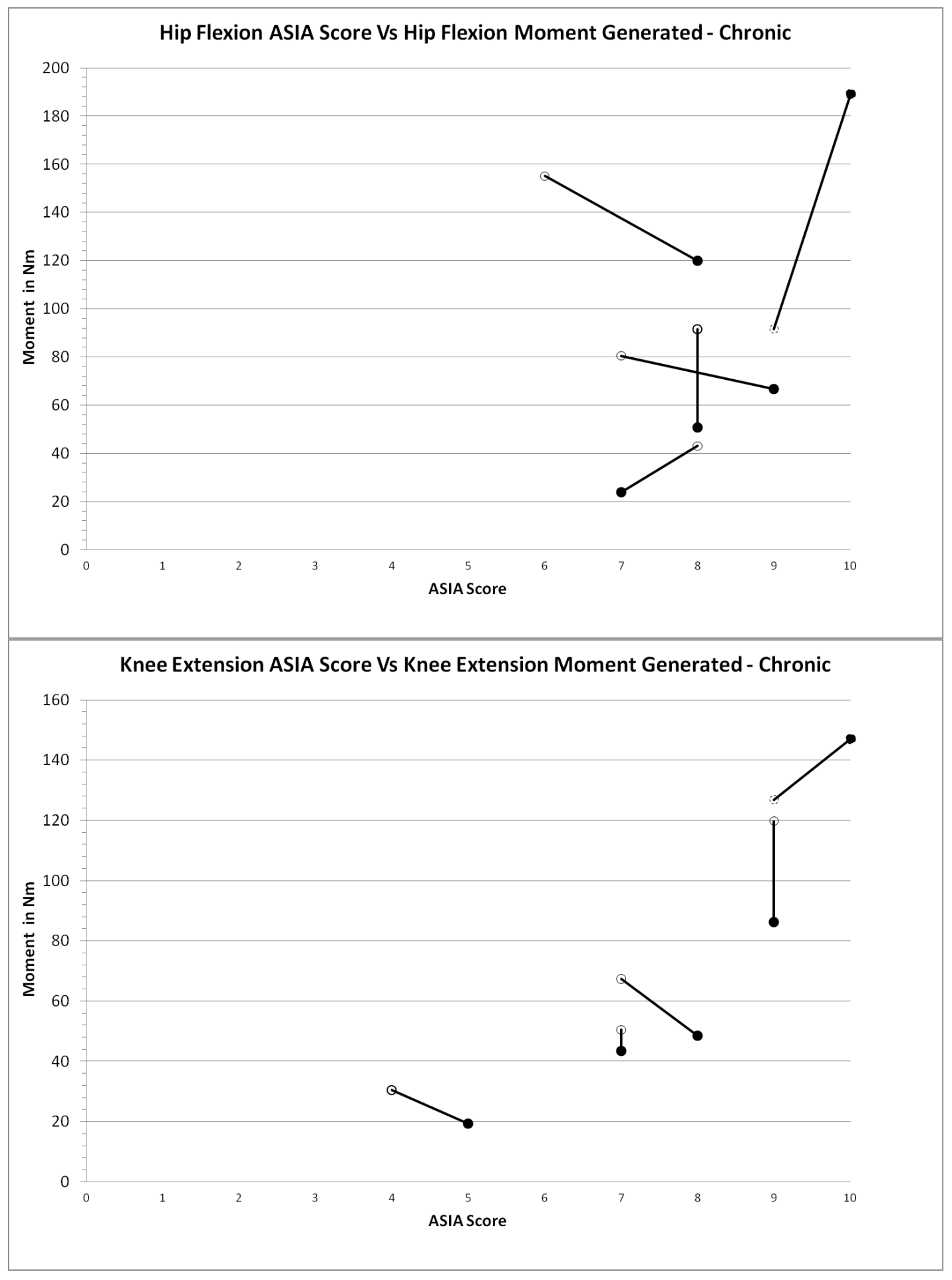

Figure $\mathbf{6 a}$ and $\mathbf{6}$ b: Peak Torque generatd as a result of isometric contraction of the hip flexor and knee extensor muscles, compared against the Lower limb motor score (ASIA Score), for each of the respective muscle in subacute/chronic subjects. Intial measures are denoted by open circles and final measures are denoted by filled circles. 